\title{
REPAIR OF INTERRUPTED AORTIC ARCH: A TEN-YEAR EXPERIENCE
}

Alain Serraf, MD

François Lacour-Gayet, MD

Monica Robotin, FRCS

Jacqueline Bruniaux, MD

Miguel Sousa-Uva, MD

Régine Roussin, MD

Claude Planché, MD
Eighty-two consecutive patients with interrupted aortic arch were referred to our institution between 1985 and 1995. Three died before any attempt at operation and 79 underwent surgical repair. Median age at operation was 9 days (range 1 day to 6 years) and median weight was $3.0 \mathrm{~kg}$ (range 1.8 to $20 \mathrm{~kg}$ ). All but one were in severe congestive heart failure and $31.5 \%$ had oliguria or anuria. Preoperative pH varied between 6.8 and 7.4 (median 7.3). Sixty-nine received prostaglandin $E_{1}$ infusion and 54 received mechanical ventilation. Aggressive preoperative ressucitation was necessary in 43 cases. Preoperative transfontanellar echography (performed routinely) since 1987 revealed intracerebral bleeding in six patients. Type $A$ interrupted aortic arch was present in 37 cases, 41 patients had type $B$, and one had type $C$. Interrupted aortic arch was associated with single ventricular septal defect in 35 cases, 24 patients had associated complex heart defects, and 30 had significant subaortic stenosis (six had both subaortic stenosis and complex association). Aortopulmonary window was found in four patients, truncus arteriosus was found in eight, and transposition of the great arteries was found in five, double-outlet right ventricle was found in one, single ventricle was found in three, multiple ventricular septal defects were found in two and superior-inferior ventricles were found in one. Sixty-four patients underwent single-stage repair and 15 underwent multistage repair. Aortic arch repair consisted of direct anastomosis in 59 cases, patch augmentation in eight, and conduit interposition in 12. Ten patients underwent associated pulmonary artery banding and 19 underwent concomitant repair of complex associated lesions. The subaortic stenosis was addressed by four surgical techniques: myotomy or myectomy in five patients; creation of a double-outlet left ventricle, aortopulmonary anastomosis, and conduit insertion between the right ventricle and pulmonary artery bifurcation in four; no direct attempt to relieve the subaortic stenosis in six; and left-sided ventricular septal defect patch in 15. Mean duration of deep hypothermic circulatory arrest, crossclamp time, and cardiopulmonary bypass time were $38.8 \pm 15.6 \mathrm{~min}, 60.5 \pm 24.7 \mathrm{~min}$, and $143 \pm 40.1 \mathrm{~min}$, respectively. Postoperative mortality rate was $18.9 \%$ ( $70 \%$ confidence limits $14 \%$ to $24.6 \%$ ), and overal mortality rate was $31 \%(70 \%$ confidence limits $20.9 \%$ to $42.2 \%$ ). The results have improved with time, with an overall operative mortality rate of $12 \%$ since 1990 . Univariate statistical analysis revealed that early survival was influenced by preoperative renal function, detection of cerebral bleeding by transfontanellar
From the Department of Pediatric Cardiac Surgery, MarieLannelongue Hospital, Le Plessis-Robinson, France.

Read at the Seventy-sixth Annual Meeting of The American Association for Thoracic Surgery, San Diego, Calif., April 28-May 1, 1996.

Received for publication May 6, 1996; revisions requested June 5, 1996; revisions received June 20, 1996; accepted for publication June 24, 1996.
Address for reprints: Alain Serraf, MD, Marie-Lannelongue Hospital, 133 Avenue de la Résistance, 92350, Le PlessisRobinson, France.

J Thorac Cardiovasc Surg 1996;112:1150-60.

Copyright $(1) 1996$ by Mosby-Year Book, Inc. $0022-5223 / 96 \$ 5.00+0 \quad \mathbf{1 2 / 6 / 7 6 0 4 3}$ 
echography, the number of cardioplegic injections, and the date of operation. Multivariate analysis revealed that preoperative renal function and the number of cardioplegic injections were independent risk factors for early mortality. Echocardiographic measurements of the left heart-aorta complex with preoperative $Z$ values as low as $\mathbf{- 4}$ demonstrated rapid growth after repair. In the presence of subaortic stenosis, better survival was obtained with a left-sided patch for ventricular septal defect closure $(p<0.05)$. Twenty-three patients underwent 26 reoperations for recoarctations (seven), left bronchial compression (two), second-stage repair (eight), right ventricle-pulmonary artery conduit replacement (three), and miscellaneous (four). One of the survivors was reoperated on for subaortic membrane. Survival at 5 years for the entire series was $70 \%$. For isolated forms, it was $73.5 \%$ (90\% for 1990 to 1995 ), for complex forms it was $\mathbf{7 0 \%}$, and in the presence of subaortic stenosis it was $60 \%$. In conclusion, interrupted aortic arch remains a surgical challenge with continually improving results. Early diagnosis with preoperative resuscitation and adequate myocardial protection seem extremely important for further improvements. Associated subaortic stenosis or complex lesions can be treated in a single-stage repair with satisfactory medium-term results. (J Thorac Cardiovasc Surg 1996;112:1150-60)

Interrupted aortic arch (IAA) is characterized by a lack of continuity between the ascending and descending thoracic aorta. It remains a rare congenital anomaly that is rapidly fatal if untreated. There is generally a persistent arterial duct that supplies blood to the lower body, and in the vast majority of cases a ventricular septal defect (VSD) is also present. IAA may also be associated with a variety of other, more complex cardiovascular anomalies, such as truncus arteriosus, aortopulmonary window, double-outlet right ventricle, and transposition of the great arteries. There is frequently some degree of obstruction or hypoplasia of the left ventricular outflow tract.

Several publications have reported improved results in terms of mortality as a result of better understanding of the anatomy, better selection of candidates for operation, and more intensive preoperative resuscitation of the patients. ${ }^{1-6}$ The last includes prostglandin $\mathrm{E}_{1}$ infusion, low-dose dopamine perfusion, and assisted ventilation. All of these preoperative maneuvers aim to improve lower body perfusion, improve renal function, diminish acidosis, and maximize the pulmonary/systemic resistance ratio across the ductus arteriosus. In addition, more refined surgical techniques have been important in improving results. The one-stage repair with direct anastomosis of the proximal to distal aortic segment has provided satisfactory patency and growth, and better outcome was observed when such single-stage repair was associated with repair of intracardiac defects.

Interestingly, some controversy persists regarding wether to treat significant subaortic stenosis (SAS) during initial repair, and a high incidence of secondary subaortic obstruction has also been described. 1, 6,7 Despite all these advances, little is known about the fate aortic anulus growth after initial repair. We report here our experience with repair of IAA during the last 10 years. Particular attention was given to the risk factors for early mortality and to the growth of the left ventricular outflow tract.

\section{Patients and methods}

Between January 1985 and December 1995, 82 consecutive infants were referred to our institution for repair of heart defects including IAA. Three died before any attempt at operation, and 79 were therefore entered into a program of surgical repair. Patients with aortic coarctation who still had a patent aortic isthmus and underwent a single-stage repair through a midsternotomy were excluded from this series. Patients without luminal continuity at the level of the aortic isthmus but in whom a fibrous chord connected across the interruption were also excluded. There were 46 male and 33 female patients. The median age at operation was 9 days (range 1 day to 6 years), the median weight was $3 \mathrm{~kg}$ (range 1.8 to $20 \mathrm{~kg}$ ), and the median body surface area was $0.20 \mathrm{~m}^{2}$ (Range 0.13 to $1.18 \mathrm{~m}^{2}$ ). All but one patient was in severe congestive heart failure. Sixty-nine received prostaglandin $E_{1}$ infusion and 54 received mechanical ventilation. The 
Table I. Patient population

\begin{tabular}{|c|c|c|c|c|c|c|c|c|}
\hline \multirow{2}{*}{$\begin{array}{c}\text { Associated cardiac } \\
\text { anomalies }\end{array}$} & \multirow{2}{*}{$\begin{array}{c}\text { Total } \\
\text { patients }\end{array}$} & \multicolumn{2}{|c|}{ Type $A(n=37)$} & \multicolumn{2}{|c|}{ Type $B(n=41)$} & \multicolumn{3}{|c|}{ Type $C(n=1)$} \\
\hline & & No. & $\%$ & $N$ & $\%$ & $N$ & & $\%$ \\
\hline VSD (isolated) & 54 & 22 & 59.4 & 31 & 75.6 & 1 & & 100 \\
\hline VSD (multiple) & 2 & 1 & 2.7 & 1 & 2.4 & & - & \\
\hline Truncus arteriosus & 8 & 2 & 5.4 & 6 & 14.6 & & - & \\
\hline AP window & 4 & 4 & 10.8 & \multicolumn{2}{|c|}{ - } & & - & \\
\hline TGA and VSD & 5 & 5 & 13.5 & \multicolumn{2}{|c|}{ - } & & - & \\
\hline Single ventricle & 3 & 1 & 2.7 & 2 & 4.9 & & - & \\
\hline DORV & 1 & 1 & 2.7 & \multicolumn{2}{|c|}{-} & & - & \\
\hline $\begin{array}{l}\text { Superior-inferior } \\
\text { ventricles }\end{array}$ & 1 & - & & 1 & 2.4 & & - & \\
\hline None & 1 & 1 & 2.7 & \multicolumn{2}{|c|}{ - } & \multicolumn{3}{|c|}{ - } \\
\hline Total & 79 & 37 & 100 & 41 & 100 & 1 & & 100 \\
\hline
\end{tabular}

$A P$, Aortopulmonary; $T G A$, transposition of the great arteries; $D O R V$, double-outlet right ventricle.

median preoperative $\mathrm{pH}$ was 7.3 , varying from 6.8 to 7.5. Preoperative ressucitation, necessary in 43 cases, included, in addition to prostaglandin $E_{1}$ and assisted ventilation, inotropic and renal support. Surgical repair was scheduled when $\mathrm{pH}$ and blood urea nitrogen were within normal ranges and when echocardiography showed an improvement in heart function. Twenty-four patients already had renal dysfunction, oligouria, elevated blood urea nitrogen, and creatininemia and were rapidly operated on despite aggressive preoperative resuscitation because of ongoing low cardiac output. Since 1987, transfontanellar echography (TFE) has been performed routinely in all cases. TFE revealed intracerebral bleeding in six, in whom CPB was therefore contraindicated. DiGeorges syndrome was diagnosed in 18 patients (five with type A IAA and 13 with type B IAA).

Sequential anatomic evaluation was performed by angiocardiography in 23 cases and by cross-sectional echocardiography alone in 56 cases. The anatomic features of the aortic arch and the site of interruption were determined according to the classification of Celoria and Patton. ${ }^{8}$ Thirty-seven patients had type $A$ IAA, 41 had type B, and one had type C. Anomalies of the supraaortic arch, including subclavian artery with retroesophageal course, were present in 12 , and two had abnormal origin of the right subclavian artery from the right pulmonary artery. The intracardiac and extracardiac associated lesions are listed in Table I. On the basis of the anatomic features and the surgical technique necessary for repair, the IAAs were divided into the following classes: isolated forms, with no associated defect other than a single VSD; complex forms associated with other heart defects; and IAA associated with subaortic obstruction. Complex forms and subaortic obstruction were both present in six neonates.

Preoperative echocardiographic measurements at different levels of the left heart outflow tract were recorded. These included the subaortic diameter, the aortic anullar diameter, and the ascending aortic diameter. A bicuspid aortic valve, was found in 30 patients. The diameters were standardized to $Z$ values by the following equation':

$Z=\log$ (Observed dimension) -

$\log$ (Mean normal dimension)/

$\mathrm{SD}$, where $S D$ is the standard

deviation of the mean normal dimension.

Surgery. Single-stage repair was always favored unless there were contraindications to cardiopulmonary bypass (CPB) or it was considered by the senior surgeon to carry too high a risk in cases of complex forms. CPB was carried out with two arterial cannulas, one in the ascending aorta and the other in the pulmonary trunk, and two venous cannulas, one in each vena cava. More recently, the pulmonary artery trunk was cannulated with an arterial cannula and the ascending aorta was cannulated with a cardioplegic needle $\mathrm{Y}$ connected to a venous line in the arterial line. The aortic arch repair was performed with the patient in deep hypothermic circulatory arrest at $20^{\circ} \mathrm{C}$ core temperature, and the remainder of the repairs were performed with continuous CPB. Techniques of myocardial protection have evolved with time. At the beginning, no cardioplegia was used, on the assumption that deep hypothermia would afford sufficient myocardial protection; later, a single blood cardioplegic infusion was used, more recently, multiple blood cardioplegia injections were administered, and even more recently, myocardial perfusion was maintained during aortic arch repair. ${ }^{5}$ The mean deep hypothermic circulatory arrest time was $38.8 \pm 15.6$ minutes, the mean crossclamp time was $60.5 \pm 24.7$ minutes, and the mean CPB time was $143 \pm 40.1$ minutes.

The technical approach for repair always followed the same principles. After resection of all ductal tissues and extensive but careful mobilization of the descending aorta, three techniques were employed to repair the aortic arch: (1) Direct anastomosis between ascending and descending aortic segments was performed in 59 cases. (2) Hemicir- 
Table II. Surgical procedures

\begin{tabular}{lcccccc}
\hline \multicolumn{1}{c}{ Lesions } & $D A$ & $P A$ & $C$ & I-stage repair & Pall, no PAB & Pall, $P A B$ \\
\hline Isolated IAA & 26 & 1 & 4 & 27 & 3 & 1 \\
IAA and SAS & 17 & 4 & 3 & 18 & 1 & 6 \\
Complex LAA & 12 & 2 & 4 & 15 & 1 & 2 \\
Complex IAA and SAS & 4 & 1 & 1 & 4 & 5 & 1 \\
Total & 59 & 8 & 12 & 64 & 10 \\
\hline
\end{tabular}

$D A$, Direct anastomosis; $P A$, patch augmentation; $C$, conduit; $P$ all, palliative repair; $P A B$, pulmonary artery banding.

cumferential anastomosis was performed between posterior aspects of the descending aorta and the remainder of the aortic arch, then the left aspect of the ascending aorta was split toward the aortic root as well as the descending aorta. The defect was then augmented with a pulmonary homograft patch. This technique was employed in eight cases. (3) Conduit interposition was performed in 12 cases (mean diameter $8.3 \mathrm{~mm}$ ). Indication for a conduit was left to the surgeon's discretion, but the largest conduit that could be inserted was always selected.

Single-stage repair was performed for 64 patients, and the other 15 had two-stage repair that included aortic contunuity restoration as part of the first procedure. Ten patients underwent concomitant pulmonary artery banding (Table II). The VSD was generally closed through a small right ventriculotomy.

Subaortic stenosis. SAS was generally the result of a posterior misalignment of the septal conus and was assessed at echocardiography by measurement of the subaortic diameter, the aortic anullar diameter, and the ascending aortic diameter. ${ }^{10}$ When the subaortic diameter was smaller than two-thirds of the aortic anullar diameter, SAS was considered to be severe. Different surgical approaches were used to deal with this anatomic arrangement: (1) Aortopulmonary anastomosis with or without creation of a double-outlet left ventricle by tunnel construction between the VSD and the pulmonary anulus and reconstruction of the right ventricle to pulmonary artery bifurcation continuity with a valved extra cardiac conduit or homograft was performed in four cases. ${ }^{11}$ (2) Resection of the conal septum was performed in five cases. ${ }^{12}$ (3) Everting suture on the conal septum to apply the patch to the left aspect of the conal septum was performed in 15 cases. ${ }^{13}$ In these cases $U$ stiches are passed through the full thickness of the conal septum from its right to left aspects by way of a small right ventriculotomy. These stitches allowed the surgeon to gently pull out the septum and to place the patch on the left aspect of the VSD. They were then passed through the patch and tied on its right ventricular side. (3) Standard VSD closure ignoring the SAS was performed in six cases. (4) Finally, in 12 cases aortic arch continuity was restored through a left thoracotomy without use of CPB. This was done either early in our experience, or later in cases with contraindications to CPB and full heparinization. This latter was the cause in six cases with preoperative neurologic disorders related to intracerebral bleeding and in one case with a solitary IAA.

Follow-up. Follow-up was achieved for $95 \%$ of the survivors by means of telephone calls and correspon- dence with the referring pediatric cardiologists. Information about the growth of the left ventricular outflow tract was particularly noted. At the time of last followup, the left ventricular outflow tract structures, including the subaortic area and the aortic annular diameter, were standardized to $Z$ values by the previously described equation. The median follow-up was 22 months (range 6 to 129 months).

Statistical analysis. Risk factors for early mortality were assessed by univariate analysis. The $t$ test was used for continuous variables and the $\chi^{2}$ test was used for dichotomous variables. Multivariate analysis was performed by stepwise logistic regression with SPSS software for Macintosh (SPSS, Inc., Chicago, Ill.). Time related events were examined by Kaplan-Meier actuarial methods. Comparisons between survival rates were performed with the log-rank test. Ratios were expressed with $70 \%$ confidence limits (CL).

\section{Results}

Survival. (Fig. 1, Table III) Survival has improved considerably throughout this 10 -year period. Overall early mortality was $18.9 \%$ (15 patients, $70 \%$ CL $14 \%$ to $24.6 \%$ ). It was $19.3 \%$ ( $70 \%$ CL $11 \%$ to $29 \%$ ) for isolated forms, $20.8 \%$ ( $70 \%$ CL $11 \%$ to $33 \%$ ) for forms with SAS, $11.1 \%$ (70\% CL $1.8 \%$ to $24.3 \%$ ) for complex forms, and 50\% (70\% CL $22.5 \%$ to $76 \%$ ) for complex forms with SAS. Analysis of the mortality rates shows that during the early period (1985 to 1990) the overall early mortality rate was $31.0 \%$ (70\% CL $20.9 \%$ to $42.2 \%$ ). In the second period (1990 to 1995), these rates changed to an overall early mortality rate of $12 \%$ ( $70 \% \mathrm{CL} 6.7 \%$ to $18.7 \%$ ), a $5.2 \%$ rate $(70 \% \mathrm{CL} 0 \%$ to $16.7 \%)$ for isolated forms, and a $16.1 \%$ rate $(70 \% \mathrm{CL} 8.3 \%$ to $25.9 \%$ ) for other forms. This difference between our early and our late experience was not statistically significant.

Risk factors for early death. Several variables were addressed by univariate and multivariate analysis to find significant risk factors. None of the demographic variables, anatomic variables, or the different surgical techniques were found to be significant risk factors for early death. Univariate 
A

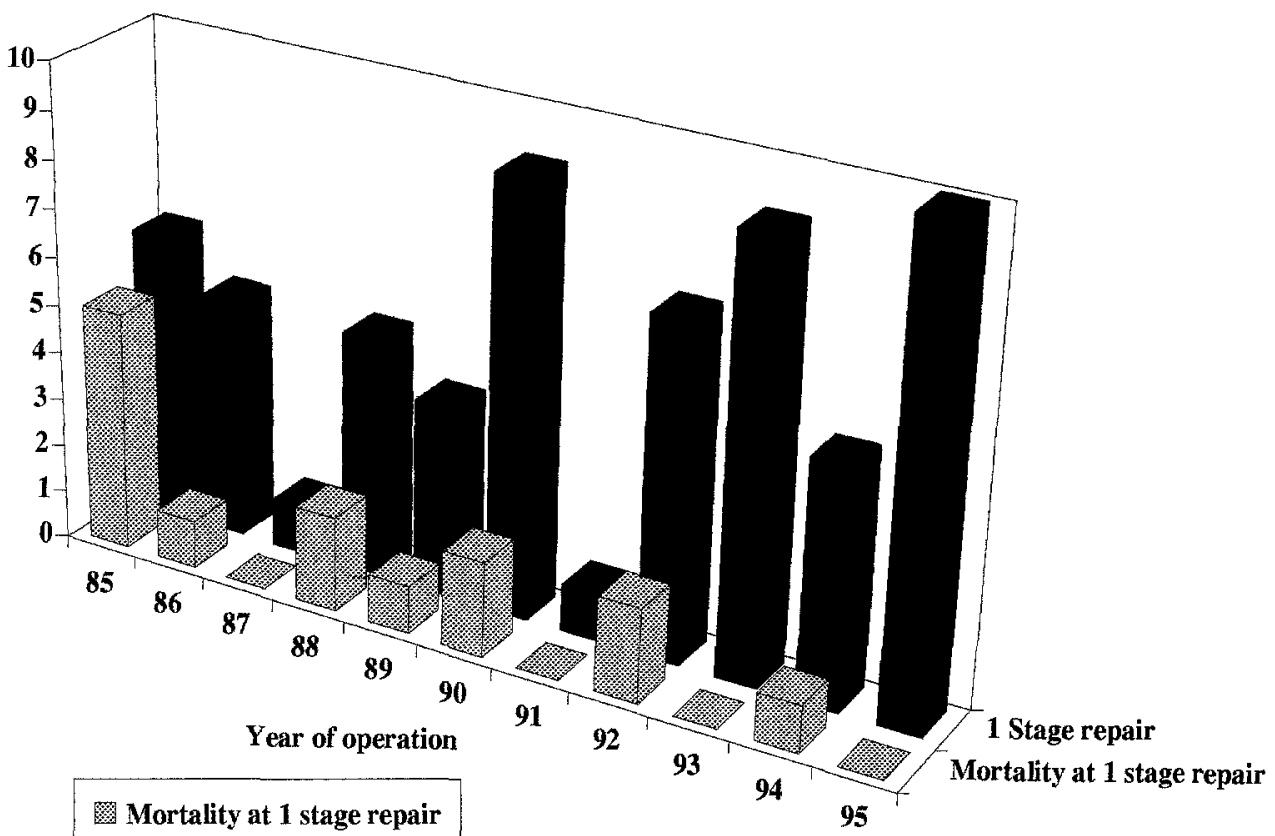

1 Stage repair

B

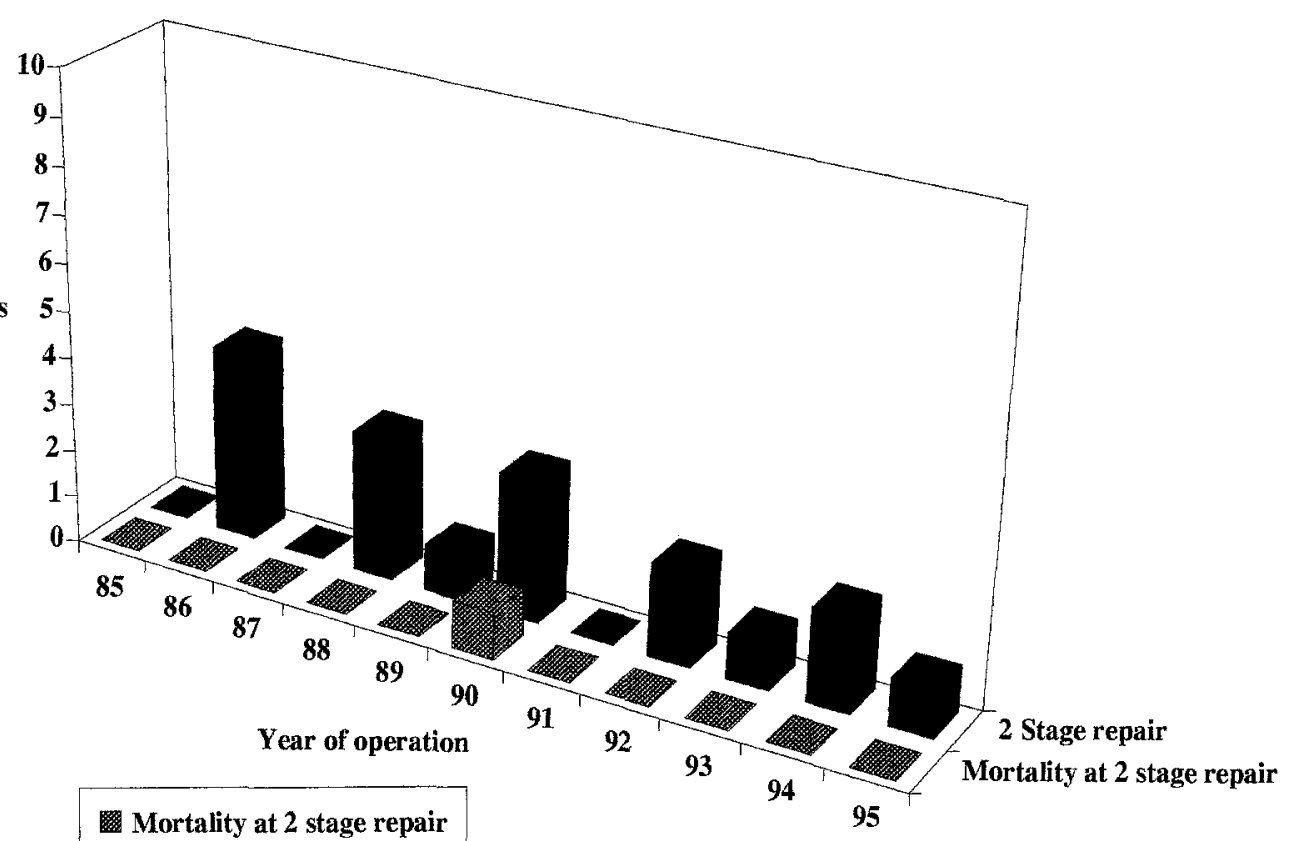

2 Stage repair

Fig. 1. Patients distribution and mortality according to year of operation and surgical technique.

statistical analysis revealed that early mortality was strongly influenced by the preoperative status (renal function and neurologic alteration from cerebral bleeding); the quality of myocardial pro- tection and the year of operation had also significant impacts on the early results. Multivariate analysis by stepwise logistic regression showed that only the preoperative renal function and the 
Table III. Results

\begin{tabular}{|c|c|c|c|c|c|c|c|c|}
\hline \multirow[b]{3}{*}{ Associated cardiac anomalies } & & & \multicolumn{6}{|c|}{ Total deaths } \\
\hline & \multicolumn{2}{|c|}{ Total $(N=79)$} & \multicolumn{3}{|c|}{ Early } & \multicolumn{3}{|c|}{ Late } \\
\hline & No. & $\%$ & No. & $\%$ & $70 \% C L(\%)$ & No. & $\%$ & $70 \%$ CL (\%) \\
\hline VSD & 31 & 39.24 & 6 & 19.3 & $11-29$ & 2 & 13.3 & $1-18$ \\
\hline Multiple VSD & 2 & 2.53 & 0 & 0 & $0-60$ & 1 & 50 & $4-93$ \\
\hline SAS & 30 & 37.97 & 5 & 16.6 & $8-26$ & 4 & 16 & $7-28$ \\
\hline Myomectomy or myectomy & 5 & 6.32 & 3 & 60 & $29-86$ & 1 & 50 & $4-93$ \\
\hline DKS & 4 & 5.06 & 0 & 0 & $0-37$ & 2 & 50 & $16-89$ \\
\hline Left sided patch & 15 & 18.98 & 0 & 0 & $0-12$ & 0 & 0 & $0-12$ \\
\hline VSD closure & 6 & 7.59 & 2 & 33.3 & $8-62$ & 1 & 25 & $0-62$ \\
\hline Truncus arteriosus & 8 & 10.12 & 2 & 25 & $5-49$ & 0 & 0 & $0-27$ \\
\hline TGA and VSD & 5 & 6.32 & 0 & 0 & $0-37$ & 2 & 40 & $11-71$ \\
\hline AP window & 4 & 5.06 & 0 & 0 & $0-31$ & 0 & 0 & $0-37$ \\
\hline Single ventricle & 3 & 3.79 & 1 & 33.3 & $0-75$ & 0 & 0 & $0-60$ \\
\hline DORV & 1 & 1.26 & 0 & 0 & $0-85$ & 0 & 0 & $0-85$ \\
\hline Superior-inferior ventricles & 1 & 1.26 & 0 & 0 & $0-85$ & 0 & 0 & $0-85$ \\
\hline None & 1 & 1.26 & 0 & 0 & $0-85$ & 0 & 0 & $0-85$ \\
\hline
\end{tabular}

$D K S$, Damus-Kaye-Stansel anastomosis; $T G A$, transposition of the great arteries; $A P$, aortopulmonary; $D O R V$, double-outlet right ventricle.

number of cardioplegic injections were independent risk factors for early mortality (Table IV).

\section{Surgical approaches}

One-stage versus two-stage repair. Fifteen patients at the first palliative procedure underwent repair of the aortic arch, associated with pulmonary artery banding in 10 cases. Reasons for preference of a two-stage repair were complex anatomy in eight cases (multiple VSDs in two, transposition of the great arteries in three, single ventricle in three), intracerebral bleeding in six, and before single-stage repair was used at all in one. Of these 15 patients, one died in the hospital, two died while awaiting complete repair, and eight could undergo secondary repair, with three deaths at complete repair in this group. There was no statistical difference in the mortality rate between single-stage or two-stage repairs.

Surgical technique for restoration of aortic arch continuity. Three techniques were employed for reconstruction of the aortic arch: direct anastomosis in 59 cases, direct anastomosis with patch augmentation in eight cases, and conduit interposition in 12 cases. Mortality was not related to the surgical technique for aortic arch reconstruction. In one case, a $5 \mathrm{~mm}$ polytetrafluoroethylene conduit was electively replaced 5 months later with a $10 \mathrm{~mm}$ conduit at the time of complete repair. At long-term follow-up, only one of the survivors who underwent conduit interposition had an arch obstruction as a result of the conduit.

Restrictive left ventricle-aorta complex. The different potentially obstructive levels throughout the left
Table IV. Statistical analysis

\begin{tabular}{lcc}
\hline \multicolumn{1}{c}{ Risk factor } & Univariate $p$ value & Multivariate $p$ value \\
\hline Renal function & 0.007 & 0.03 \\
TFE & 0.02 & NS \\
No cardioplegia & 0.0002 & 0.03 \\
Operation before 1990 & 0.02 & NS \\
\hline
\end{tabular}

$N S$, not significant.

ventricular outflow tract were examined. Thirty patients had SAS; in 15, the subaortic diameter was less than two-thirds of the aortic anular diameter. Distribution of the $Z$ values is depicted in Fig. 2 . Mortality was not influenced by the size of the left ventricular outflow tract. The subaortic obstructions were surgically addressed by four main surgical techniques: (1) resection of the conal septum in five patients, creation of a double-outlet left ventricle associated with aortopulmonary anastomosis and conduit insertion between the right ventricle and pulmonary artery bifurcation in four patients, no direct attempt to relieve the subaortic obstruction in six patients, and application of the upper edge of the patch to the left aspect of the conal septum in 15 patients. The last technique was associated with no deaths and a $100 \%$ survival $(p<0.05$ vs other approaches for SAS).

Complex associations. Twenty-four patients had complex heart defects that included an IAA (Table I). This subgroup had actuarial survivals of $83.3 \%$ and $70.5 \%$ at 1 month and 5 years, respectively. Nineteen patients in this subgroup underwent sin- 


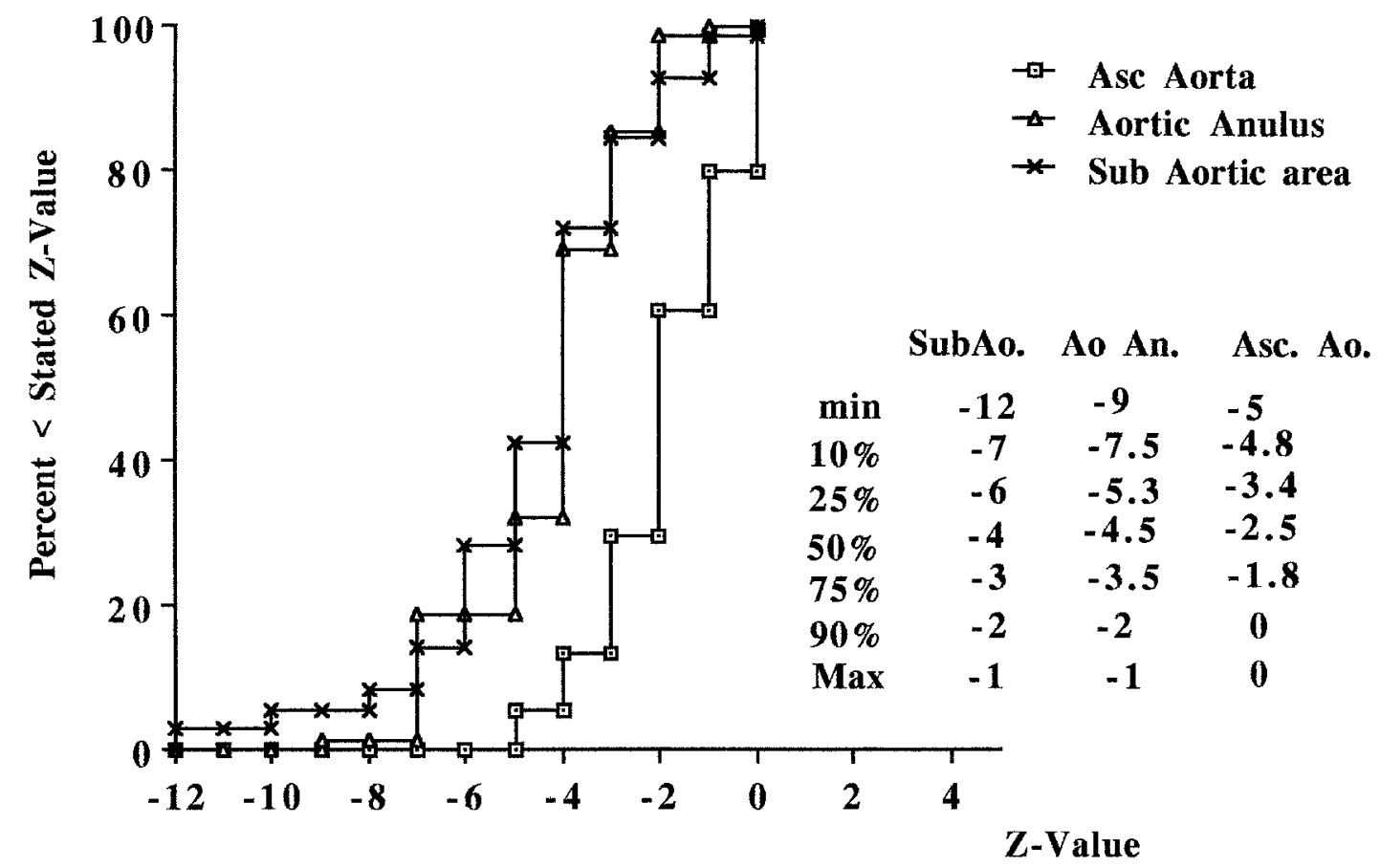

Fig. 2. $Z$ value distribution at birth (before operation). $A s c$, Ascending; $A o$, aorta.

Table V. Reoperations

\begin{tabular}{lc}
\multicolumn{1}{c}{ Cause } & No. \\
\hline Recurrent coarctation & 7 \\
Residual VSD & 1 \\
Subaortic membrane resection & 1 \\
AV block & 2 \\
Reconstruction of RVOT & 1 \\
Secondary closure of VSD with PAB removal & 4 \\
ASO & 3 \\
Replacement of RV-PA conduit & 3 \\
Cavopulmonary anastomosis & 1 \\
Bronchial compression & 2 \\
Diaphragmatic plication & 1 \\
\hline
\end{tabular}

$A V$, Atrioventricular; $R V O T$, right ventricular outflow tract; $P A B$, pulmonary artery band; $A S O$, arterial switch operation; $R V$, right ventricle; $P A$, pulmonary artery.

gle-stage repair; five underwent two-stage repair. The latter approach had no negative influence on survival. Complex association with IAA had no statistical impact on early and late mortality.

Follow-up. A mean follow-up of $39 \pm 40$ months was achieved for $95 \%$ of survivors. Accurate information about heart measurements could be obtained for $40(72 \%)$; all others without such information were known to be alive at the time of this study.

Reoperations. Twenty-three patients underwent 26 reoperations (Table $V$ ) for a residual or recur- rent defect, either to undergo complete repair after a palliative first stage or because of the natural evolution of the underlying type of initial repair. There were three deaths at reoperation: two patients with transposition of the great arteries and one with severe obstruction of the pulmonary bifurcation as a result of the pulmonary artery band.

Growth of the left ventricular outflow tract. Among the 55 long-term survivors, only two had a subaortic membrane; one of these underwent reoperation. None of the others had significant subaortic obstruction. Furthermore, the aortic anulus had grown to nearly normal values at last echocardiographic assessment. Fig. 3 depicts the $Z$ value distribution for the left side of the heart. Isthmic recurrent anastomotic stenosis with a gradient greater than $30 \mathrm{~mm}$ $\mathrm{Hg}$ occurred in 15 patients (27.2\%). Seven underwent reoperation, five underwent balloon angioplasty, and three are still waiting for a further procedure. Interestingly enough, the surgical technique for aortic arch repair was not a risk factor for development of recurrent arch obstruction; in particular, those with conduit insertion did not have this type of complication. A $5 \mathrm{~mm}$ polytetrafluoroethylene conduit was electively replaced at the time of complete repair in one patient. 


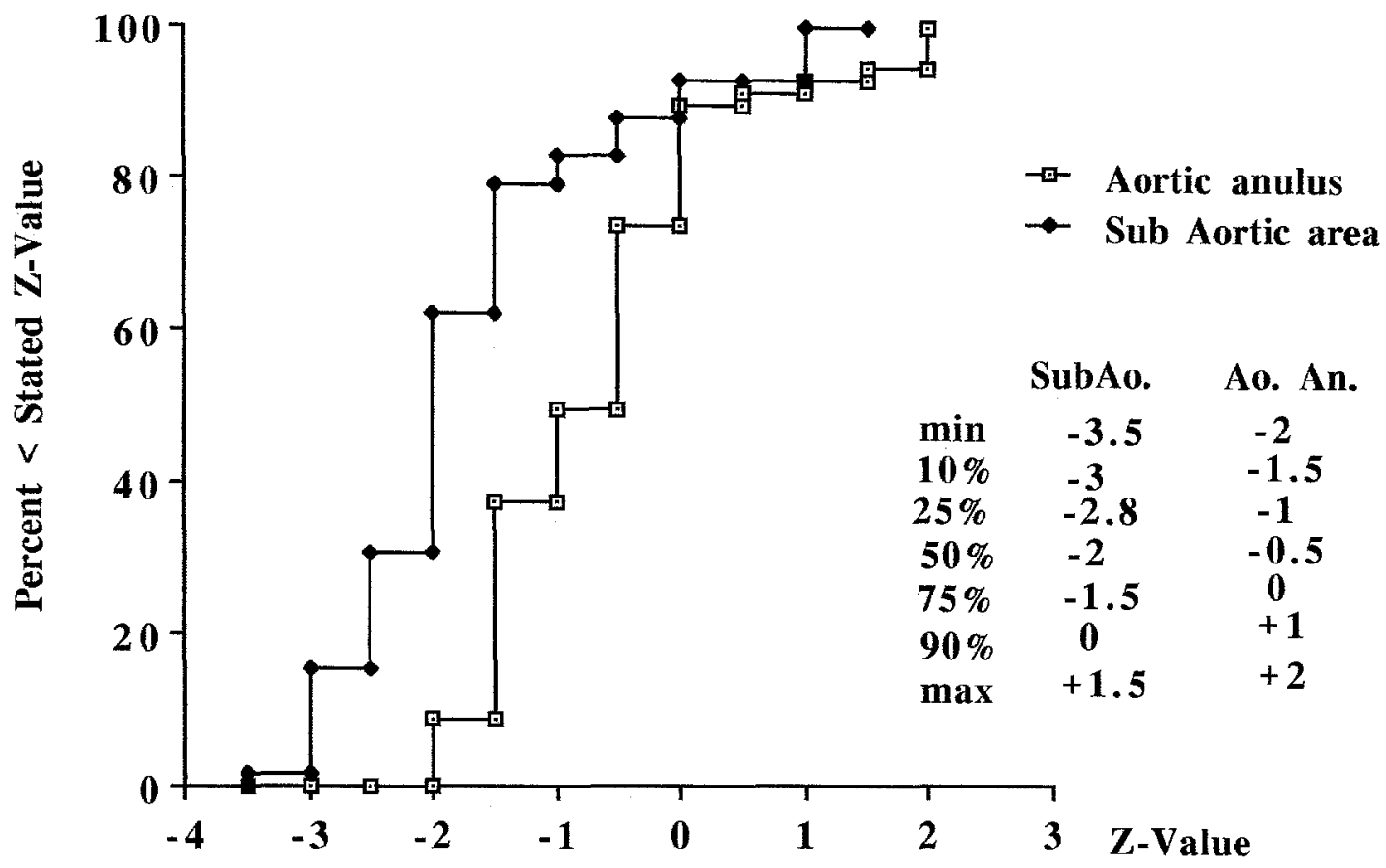

Fig. 3. $Z$ value distribution at a median follow-up of 22 postoperative months ( 40 patients). Diameters of ascending aorta were not available. Ao, Aorta.

Status of survivors. Among the 64 hospital survivors, there were nine secondary deaths. Two occurred after palliation while awaiting complete repair; three occurred after complete secondary repair. Three other infants died between 3 and 6 months after operation without evidence of residual cardiac defects. Another died 2 years later of graftversus-host reaction after bone marrow transplantation. Among 55 long-term survivors, 53 could be traced; in the case of one overseas patient, the last information was obtained in April 1993, 3 years after initial operation. All were in New York Heart Association functional class 1 or 2, and only three still received afterload-reduction therapy.

Actuarial survival rate at 5 years was $70 \%$ for the overall series. Rates were $73.5 \%$ for isolated forms, $70.6 \%$ for complex forms, and $60 \%$ for those with SAS (Fig. 4). There were no statistically significant differences among these survival rates. Overall 5-year survival rate for patients undergoing twostage repair was $60 \%$, versus $70.3 \%$ for those who underwent single-stage repair. In addition, comparison of the survival rates among patients undergoing two-stage procedures from the point of completion of both stages with rates of those undergoing singlestage procedures did not show a statistically significant difference ( $75 \%$ vs $70.3 \%$ ).

\section{Discussion}

A recent publication on a multiinstitutional study undertaken by the Congenital Heart Surgeons Society reported several important conclusions with respect to the risk factors for early death after repair of IAA. ${ }^{6}$ These conclusions were not fully supported by our retrospective study. In our study, none of the demographic, anatomic, and surgical variables analyzed were risk factors for early death. Only the preoperative status and the adequacy of myocardial preservation seemed to influence the early outcome. Although most of the critically ill neonates with IAA had aggressive preoperative resuscitation, some required prompt operations because of ongoing low cardiac output and organ failure that did not improve despite medical support. Also, univariate and multivariate analyses of the number of cardioplegic injections during repair revealed that multiple-dose cardioplegia was associated with better survival. Although experimenters continue to debate optimal myocardial protection for immature hearts, ${ }^{14}$ it is evident from this study that multiple-dose cardioplegia was better than the other methods.

Another important issue reported in this study was the usefulness of TFE to detect preoperative intracerebral bleeding. TFE detected such bleeding 


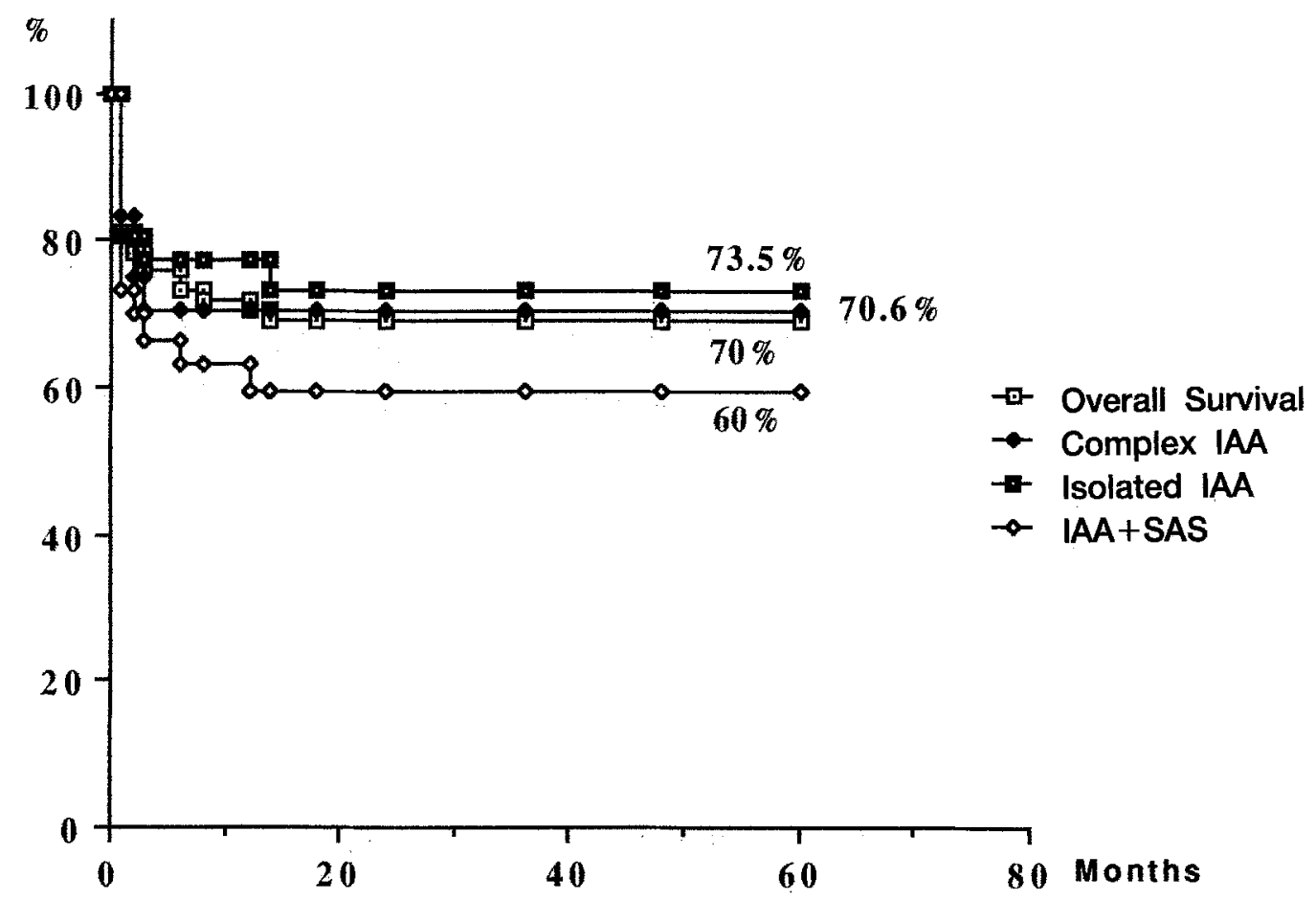

Fig. 4. Five-year actuarial survival.

before operation in six patients, who therefore underwent early palliation without CPB. Three other patients died after complete repair under CPB of neurologic complications found at postmortem examination to be related to cerebral bleeding.

Beyond the postoperative period after singlestage repair, there continued to be attrition rate, which tended to reach a plateau at 6 months after repair. On the other hand, patients who underwent palliation had a higher attrition rate both during the intermediary period while awaiting repair and at the time of complete repair. A single-stage repair should therefore be recommended whenever feasible.

Left ventricular outflow tract size has been a source of several discussions. What is the minimal diameter of the aortic anulus below which standard repair is not acceptable? What is the best approach to deal with SAS? From this and other studies, the mean $Z$ values of the aortic anulus and subaortic area were -4 , but some patients had $Z$ values as low as -9 . These small left ventricular outflow tracts were not incompatible with a standard biventricular repair; moreover, these sizes tended to approximate the normal value at last follow-up (Fig. 2). The patient with the smallest aortic anulus in this series
( $3 \mathrm{~mm}$ ) demonstrated rapid growth, with an aortic anullar diameter of $8 \mathrm{~mm}$ at 6 months after operation. The same observation was true for the subaortic area, particularly when there was no obvious SAS. In the presence of SAS, several procedures have been proposed. ${ }^{11-13,15,16}$ Early in our experience, we had been concerned by this anatomic condition, and we therefore opted for different surgical techniques such as creation of double-outlet left ventricle with aortopulmonary anastomosis and right ventricle-pulmonary artery continuity reconstruction or myectomy. These procedures did not improve early survival and even carried high mortality rates. We then moved to a simpler technique that was recently published by Luciani and colleagues. ${ }^{13}$ The patch for closure of the VSD is applied on the left side of the septum to pull the conal septum into the right ventricle. With this technique, there were no related deaths and the subaortic area demonstrated satisfactory growth.

Only two patients, one of whom underwent reoperation, had subaortic membranes. The mean left ventricle to aorta gradient at 2 years of follow-up was $6.25 \pm 10.1 \mathrm{~mm} \mathrm{Hg}$. We therefore believe that a standard repair should be done regardless of the anatomic characteristics of the left heart-aorta com- 
plex, assuming that these areas will grow after reestablishment of a pulmonary to systemic resistance ratio of 1:1. In cases with a left heart-aorta complex smaller than $3 \mathrm{~mm}$, however, we have no data to support this concept, and such cases probably should be considered as aortic atresia. Techniques for repair of the aortic arch have also been debated. Direct anastomosis with arch and ascending aorta patch augmentation has been advocated by several authors, ${ }^{6,17}$ assuming that no (or few) operations will be required for recurrent stenosis and that augmentation would promote growth of left heart structures. Again, our data do not support this theory, because 59 patients had direct anastomosis without patch augmentation and only nine required a procedure (operation or angioplasty) for reccurrent stenosis. Moreover, direct anastomosis without patch augmentation was not a cause of insufficient growth of the left heart-aorta complex. On the other hand, in complex IAA with truncus arteriosus, transposition of the great arteries, or single ventricle, patch augmentation appears to be an important adjunct to the surgical technique for completion of a widely patent aortic anastomosis to cope with the size mismatch of the great arteries.

Association of complex malformations remains a surgical challenge with demanding techniques. ${ }^{18-20}$ In most of these forms, palliation has proved to be unsatisfactory and complete repair should be undertaken at birth. This was particularly the case for patients with truncus arteriosus and aortopulmonary window. There were five cases of transposition of the great arteries and IAA; two of these patients underwent neonatal complete repair with no deaths, and three underwent a two-stage repair with two deaths at time of the arterial switch operation. Although this represents a limited subseries, the neonatal single-stage repair is now favored in this subset. There were three patients with single-ventricle physiology; two underwent a Norwood-type procedure and could have a second stage bidirectional Glenn anastomosis. The third patient underwent repair of the aortic arch with pulmonary artery banding and died early of severe SAS. This experience with patients with single-ventricle physiology and systemic obstruction has been published elsewhere, ${ }^{21}$ and its results strongly favored agressive neonatal surgical relief from all potential residual systemic obstruction by the Norwood procedure. Finally, in the current era, the operative risk for a neonate with IAA and VSD is $5 \%$, with a 5 -year survival of $90 \%$. Association with SAS and complex malformations reduce the 5-year survivals to $60 \%$ and $70 \%$, respectively.

In conclusion, IAA remains a surgical challenge with continually improving results. Early diagnosis, preoperative ressucitation, and adequate myocardial protection seem to be of extreme importance for further improvement. Associated SAS or complex lesions can be treated by single-stage repair with satisfactory medium-term results.

\section{Addendum}

Since the submission of this article, a 3-year-old patient who had undergone a single-stage repair for type B IAA elsewhere as a neonate was referred to our department for treatment of severe aortic valve stenosis and SAS. A Ross procedure was scheduled. Preoperative assessment showed that the pulmonary valve has been impaired, however, probably by closure of the VSD through the pulmonary trunk. This finding was confirmed at operation, and the patient instead underwent an aortic commissurotomy associated with subaortic resection of fibrous tissue. This observation raises a point of caution regarding subsequent Ross procedures in patients in whom the VSD is closed through the pulmonary trunk.

\section{REFERENCES}

1. Sell JE, Jonas RA, Mayer JE, Blackstone EH, Kirklin JW, Castaneda AR. The results of a surgical program for interrupted aortic arch. J Thorac Cardiovasc Surg 1988;96: 864-77.

2. Vouhé PR, Macé L, Vernant F, et al. Primary definitive repair of interrupted aortic arch with ventricular septal defect. Eur J Cardiothorac Surg. 1990;4:365-70.

3. Irwin ED, Braunlin EA, Foker JE. Staged repair of interrupted aortic arch and ventricular septal defect in infancy. Ann Thorac Surg 1991;52:632-9.

4. Hazekamp MG, Quaegebeur JM, Singh S, et al. One stage repair of aortic arch anomalies and intracardiac defects. Eur J Cardiothorac Surg 1991;5:283-7.

5. Karl TR, Sano S, Brawn W, Mee RB. Repair of hypoplastic or interrupted aortic arch via sternotomy. J Thorac Cardiovasc Surg 1992;104:688-95.

6. Jonas RA, Quaegebeur JM, Kirklin JW, Blackstone EH, Daicoff $G$. Outcomes in patients with interrupted aortic arch and ventricular septal defect: a multiinstitutional study. J Thorac Cardiovasc Surg 1994;107:1099-113.

7. Scott WA, Rocchini AP, Bove EL, et al. Repair of interrupted aortic arch in infancy. $J$ Thorac Cardiovasc Surg 1988;96:564-8.

8. Celoria GC, Patton RB. Congenital absence of aortic arch. Am Heart J 1959;58:407-12.

9. Kirklin JW, Barratt-Boyes BG. Cardiac surgery. 2nd ed. New York: Churchill Livingstone, 1993:21-6.

10. Al Marsafawi HM, Ho SY, Redington AN, Anderson RH. The relationship of the outlet septum to the aortic outflow tract in hearts with interruption of the aortic arch. J Thorac Cardiovasc Surg 1995;109:1225-36.

11. Yasui H, Kado H, Nakano E, et al. Primary repair of interrupted aortic arch and severe aortic stenosis in neonates. J Thorac Cardiovasc Surg 1987;93:539-45. 
12. Bove EL, Minich L, Prijdan AK, et al. The management of severe subaortic stenosis, ventricular septal defect and aortic arch obstruction in the neonate. $\mathbf{J}$ Thorac Cardiovasc Surg 1993;105:289-96.

13. Luciani GB, Ackerman RJ, Chang AC, Wells WJ, Starnes VA. One-stage repair of interrupted aortic arch, ventricular septal defect and subaortic obstruction in the neonate: a novel approach. J Thorac Cardiovasc Surg 1996;111:348-58.

14. Magovern JA, Pae WE, Miller CA, Waldhausen JA. The immature and mature myocardium: responses to multidose crystalloid cardioplegia. J Thorac Cardiovasc Surg 1988;95: 618-24.

15. Ilbawi MN, Idriss FS, DeLeon SY, Muster AJ, Benson WD, Paul MH. Surgical management of patients with interrupted aortic arch and severe subaortic stenosis. Ann Thorac Surg 1988;45:174-80.

16. Jacobs ML, Chin AJ, Rychik J, Steven JM, Nicolson SC, Norwood WI. Interrupted aortic arch: impact of subaortic stenosis on management and outcome. Circulation 1995; 92(Suppl 2):II128-31.

17. Dietl CA, Torres AR. Repair of interrupted aortic arch with an augmented aortic anastomosis. Ann Thorac Surg 1993;56:142-8.

18. Sano S, Brawn WJ, Mee RB. Repair of truncus arteriosus and interrupted aortic arch. J Cardiac Surg 1990;5:157-62.

19. Mc Kay R, Miyamoto S, Peart I, et al. Truncus arteriosus with interrupted aortic arch: successful correction in a neonate. Ann Thorac Surg 1989;48:587-9.

20. Ingram MT, Ott DA. Concomitant repair of aortopulmonary window and interrupted aortic arch. Ann Thorac Surg 1992; 53:909-11.

21. Serraf A, Conte S, Lacour-Gayet F, et al. Systemic obstruction in univentricular hearts. Surgical options with particular emphasis on the neonatal management. Ann Thorac Surg $1995 ; 60: 970-7$.

\section{Discussion}

Dr. Richard A. Jonas (Boston, Mass.). I congratulate you and your colleagues on a lucid analysis of an outstanding surgical series of patients with IAA.

In 1994, I had the privilege of analyzing, in conjunction with Drs. Kirklin and Blackstone, the results of a prospectively enrolled series of 250 neonates operated on by members of the Congenital Heart Surgeons Society (CHSS). Although there are some important differences between the two series, the conclusions that we came to are similar to your conclusions.

One of the interesting differences is the lower incidence of patients with type B IAA. In the CHSS series, $79 \%$ of the patients had type $B$ interruption, in contrast to about $52 \%$ in your series. In the CHSS series, type B interruption was a risk for death at any time.

You were able to identify only preoperative renal function and single-dose cardioplegia as risk factors for death. In contrast, the CHSS series identified, in addition to type $\mathrm{B}$ interruption, lower birth rate, younger age at repair, outlet VSD, smaller VSD, SAS, stenosis, and use of a Damus-Kaye-Stansel-type repair. The last factor is important because there is a risk that the small size of the left ventricular outflow tract (which is almost always small) might tempt surgeons to alter their operative repair to bypass the SAS by a Damus-Kaye-Stansel-type repair or to resect the SAS. In the CHSS series, both these approaches were associated with significantly higher risk of death. I note that in your series, two of four patients who underwent Damus-Kaye-Stansel-type anastomosis repair died, and four of five who underwent subaortic resection ultimately died. That these factors did not appear in either multivariate or univariate analysis as risk factors presumably reflects the small sample and highlights the advantages of a multiinstitutional study for rare anomalies such as IAA. You have nevertheless concluded, as did we, that a standard repair should be applied unless the subaortic area is smaller than a $Z$ score of approximately -9 , corresponding in the average neonate to a narrowest dimension of about $3 \mathrm{~mm}$.

I am intrigued that you found multidose cardioplegia to be associated with better survival. This has not been our experience, and we continue to use single-dose cardioplegia for neonates. Have you had similar experiences with other neonatal repairs, such as the arterial switch, and have you moved to multidose cardioplegia for all neonatal procedures? Can you tell us something about your current technique of myocardial protection for neonates and speculate regarding what differences from other groups might explain your improved results with multidose cardioplegia?

Dr. Serraf. Although several experimental studies have shown that multidose cardioplegia was less than optimal for neonatal myocardial protection, in the clinical arena we have observed the opposite effect. In our population with transposition of the great arteries who underwent an arterial switch operation before the first month after birth, multidose cardioplegia, either blood or cristalloid, was associated with better survival, lower rate of delayed sternal closure, and shorter intubation time. We could also demonstrate by serial echocardiographic studies in the intensive care unit that the myocardial performance was significantly better with this type of myocardial protection. When only analyzing the shortening fraction, the immediate postsurgical values were higher with multidose cardioplegia than with single-dose cardioplegia to begin with. Moreover, recovery to normal values was faster with this type of myocardial protection than with single-dose cardioplegia. These observations have prompted us to use multidose cardioplegic infusions for all neonatal cardiac repairs. The quality of postoperative myocardial performance, however, is probably multifactorial. In our setting of continuous CPB, the cardioplegic solution is not sucked to the pump reservoir but to the wall suction, and therefore the use of multidose cardioplegia does not increase the pump volume. We wonder whether if it was sucked to the pump there would not have been an equivalent of volume overload and too high hemodilution, with an increase of total body water content and subsequent myocardial edema. 